Seminar Nasional Teknologi Informasi dan Kedirgantaraan (SENATIK)

Vol. II, 26 November 2016, ISSN: 2528-1666

\title{
The Effects Of Mixing And Curing On Morphological And Mechanical Properties Of Epoxy-Albasia Composites
}

\author{
HennyPratiwi \\ Aeronautics Department, Sekolah Tinggi Teknologi Adisutjipto \\ JlJanti Blok R Lanud Adisutipto, Yogyakarta \\ henny_pratiwi@stta.ac.id
}

\begin{abstract}
This research is aimed to know the effect of mixing time, mixing speed and curing temperature on morphological and mechanical properties of epoxy-albasia wood fiber composites. The method used in the manufacturing process was hand lay-up method. The fiberswith 30 mesh and $25 \%$ volume fraction are mixed with epoxy for the time variations of 15 and 45 minutes by speed variation of $695 \mathrm{rpm}, 773 \mathrm{rpm}$, and $853 \mathrm{rpm}$. In order to investigate the effects of curing temperature, the same mixture wasblended manually for 20 minutes and cured with the temperature variation of 40, 50, 60, 70 and $80^{\circ} \mathrm{C}$. Experimental results show that mixing the fiber and matrix with the speed of 695 rpm for 15 minutes increases the tensile strength but slightly declines the impact strength. This phenomenon could be possibly caused by the longer the mixing time, the higher the amount of foreign particles entered into the mixture that could affect its properties. Both the tensile and impact tests show that the temperature of $80^{\circ} \mathrm{C}$ is the optimum curing temperature for epoxy-albasia wood fiber composites. Crack deflection presented by Scanning Electron Microscopy (SEM) micrographs results in an increase in the crack propagation path and in the energy-dissipating events in the region immediately ahead of the crack tip.
\end{abstract}

Keywords: albasia, epoxy, mixing, curing, mechanical

\section{Introduction}

The use of wood-based materials (wood flour and wood fibers) as reinforcing fillers for thermosettings has received great attention from a number of researchers and manufactures in recent years. The addition of the renewable natural fiber in polymeric composites aims to produce unique characteristics of great versatility, light weight, biodegradability and recyclability with good specific properties. In comparison with other fibers such as traditional glass fiber and inorganic mineral fillers, wood is inexpensive, low density and non-abrasive to processing machinery [1-3].

During recent years there has been special interest in developing polymers made using lignocellulose fibers as reinforcing fillers and to reduce raw material costs. Although these improvements are not new developments the material is essentially renewable and can be made by employing recycled polymer and wood industry waste.
A major issue in achieving true reinforcement from the incorporation of natural fibers into wood is the inherent incompatibility between the hydrophilic fibers and the hydrophobic polymers, which results in poor adhesion and therefore in poor ability to transfer stress from the matrix to the reinforcing fiber. A number of investigators have explored the ability of additives to enhance adhesion and thereby improve properties such as tensile and flexural strength of these composite materials.

Sarawut et al. [4] have observed polypropylene composites filled with Hevea Brasilliensis wood flour at filler content up to $60 \mathrm{wt} \%$ in order to determine the effects of polymer melt flow rate (MFR), number of reprocessing times, filler size, and filler content on thermal and mechanical properties. The results reveal that the composites of polypropylene with higher melt flow rate (lower viscosity) provided greater values of flexural and tensile properties. The study additionally exhibits the recyclability potential without losing mechanical 
properties. Furthermore, both flexural and tensile modulus increased, while both flexural and tensile strength decreased with increasing wood flour contents. In addition, the average particle size of wood flour that was suitable for improving the mechanical properties was approximately 200-300 $\mathrm{mm}$. In the last section of the research, the effects of maleic anhydride grafted polypropylene (MAPP) coupling agent were investigated. It is worth noting that, the flexural strength and tensile strength of highly filled composites with MAPP at 5wt $\%$ (based on wood flour) were approximately $110 \%$ and $87 \%$ higher than those of the composites without MAPP, respectively.

Selke and Wichman [5] compared the virgin HDPE and recycled HDPE to obtain the best mechanical properties of wood plastics composites. From the research, it can be concluded that the performance of composites made from recycled HDPE was at least as good as that of composites made from virgin HDPE. In most cases, differences between the recycled and virgin matrix composites were not statistically significant.

The flexural strength and rigidity of albasia nail-laminated beam have been investigated by Tjondro et al. [6]. The research showed that the vertically nail-laminated beam has greater strength and rigidity than horizontally nail-laminated beam, but less in ductility. The vertically nail-laminated beam rigidity factor can achieve more than 0.7 , but horizontally nail-laminated beam really depends on the nail spacing and is lower than vertically laminated beam. The average ratio of load at proportional limit to the load at allowable displacement gives the safety factor of more than 1.6 which is commonly sufficient for allowable stress design. Shear failure in the web of I vertically nail-laminated beam needs more investigation.

Mechanical performance of cold-curing epoxy adhesives after different mixing and curing procedures have been investigated by Michels et al. [7]. The research presents strength, stiffness, and porosity characteristics of commercially available coldcuring epoxy adhesives for structural engineering applications in the field of externally bonded and/or near-surface mounted composite strip reinforcements. Depending on specific requirements, accelerated curing of the adhesive under high temperatures might be necessary. Experimental investigations aimed at assessing the possible differences in strength and stiffness between samples cured at elevated temperatures for a defined time span and the ones cured at room temperature. It could be demonstrated that for the same specimen age, nominal tensile strength and stiffness are lower after an initial accelerated curing process at elevated temperatures. Furthermore, it could be shown that the specimens after an accelerated curing at elevated temperatures exhibited an increased porosity. The development of a numerical code for image analysis allowed a detailed inspection of several fracture surfaces and subsequently to assess the level of decrease in available cross-section due to an increased overall porosity. Cross-section area losses in the range of 10 to $15 \%$ compared to the reference specimens could be deduced. The sub-sequent derivation of the actual tensile strength exhibits smaller differences between the room and high temperature exposed specimens while curing. Regardless of the short-term material strength, the observed porosity might be subject of important durability issues on a long-term and needs further investigation.

This paper summarizes some of the research involving composites with wood fibers and epoxy that has been carried out at Sekolah Tinggi Teknologi Adisutjipto in order to obtain the best morphological and mechanical properties.

\section{Experimental Method}

Albasia wood fiber which ranged from 20 until 30 mesh, general purpose resin-epoxy (Bisphenol A- epichlorohydrin) Bakelite EPR 174 and hardener versamid 140 were used in this research. At first, the fiber was sieved to obtain a size of 30 mesh and then dried. Furthermore, epoxy and 25\% volume fraction of albasia fiber mixed with the time variations of 15 and 45 minutes by speed variation of $695 \mathrm{rpm}, 773 \mathrm{rpm}$, and $853 \mathrm{rpm}$ using a mixer. After the mixture was well blended, it was added with hardener and stirred again to make the fiber and matrix mixed evenly. The mixture was poured into the mold and then put into oven for 40 minutes with the temperature of $60^{\circ} \mathrm{C}$. In order to investigate the effects of curing temperature, the other batch of mixture, which contains epoxy and 25\% volume fraction of albasiawood fiber mixed manually for 20 minutes and cured with the temperature variation of $40,50,60,70$ and $80^{\circ} \mathrm{C}$. 


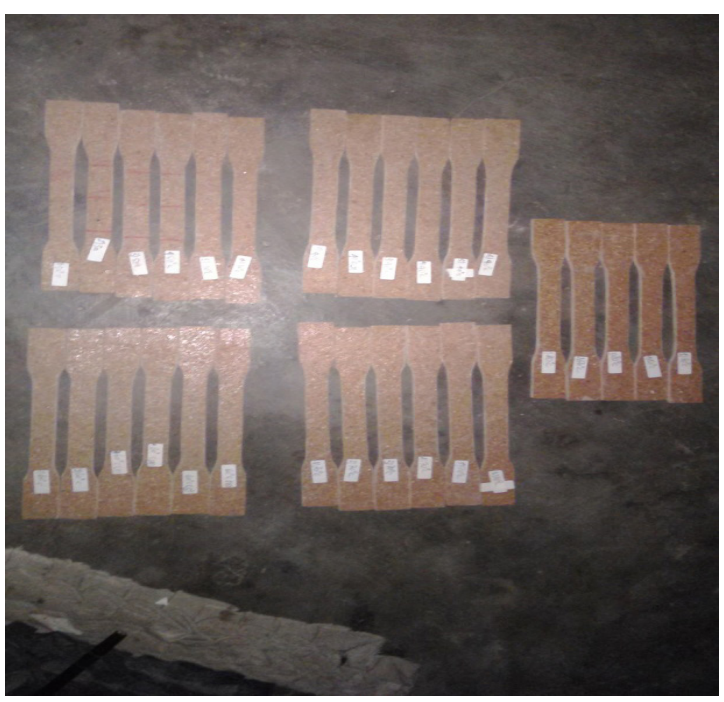

Figure 1 Tensile test specimen of albasia wood fiber-epoxy matrix composites

Tensile tests were performed using universal tensile machine (UTM, Torsee AMU-5-DE) and the specimen was prepared by referring to ASTM D638-02. The Charpy impact test was also conducted based on ASTM D5942-96 standard. For every set of variation, 5 specimens were tested to determine the average tensile strength. The tests were conducted at a standard laboratory atmosphere of $25^{\circ} \mathrm{C}$ and $60 \%$ relative humidity. Later, the morphology of fiber and matrix interface and also failure surface of different specimens was investigated using Scanning Electron Microscopy (SEM) machine.

\section{Results And Discussion}

\subsection{Effects of Mixing Speed and Mixing Time}

Epoxy polymers are classified as a brittle material because these materials usually fail in tension at relatively low values of strain [8]. As mentioned before, tensile test is conducted to measure the force required to break a polymer composite specimen and the extent to which the specimen stretches or elongates to that breaking point. The tensile test is conducted for the specimens that have $25 \%$ volume of albasia wood fiber, with the mixing speed variation of 695,773 and $853 \mathrm{Rpm}$ and mixing time variation of 15 and 45 minutes (Fig. 2).

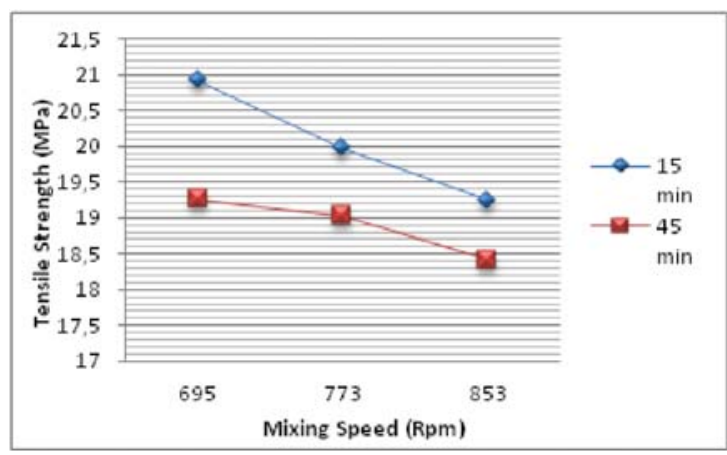

Figure 2 Tensile strength results of $25 \%$ volume fractionalbasia wood-epoxy composites for different mixing speed and time

Based on the investigation, we can conclude that the higher the mixing speed and the longer the mixing time, the lower the strength. This phenomenon could be possibly caused by the longer the mixing time, the higher the amount of foreign particles entered into the mixture that could affect its properties. It is almost the same with the mixing speed which the higher mixing speed could cause the void became developed and buried in the composites. Voids are a common microstructural feature in composite materials, particularly when non-autoclave manufacturing processes are used, resulting either from entrapped air during the manufacturing process or from volatiles arising from the resin during the cure stage [9].

The other researcher [10] found that the mechanical properties, including the tensile strength, flexural strength and flexural modulus of the composites, declined with the increase of the void content. Koushyar et al. [11] discovered that interlaminar shear strength (ILSS) of carbon fiber reinforced epoxy composites decreased exponentially with the increase of the void content. 

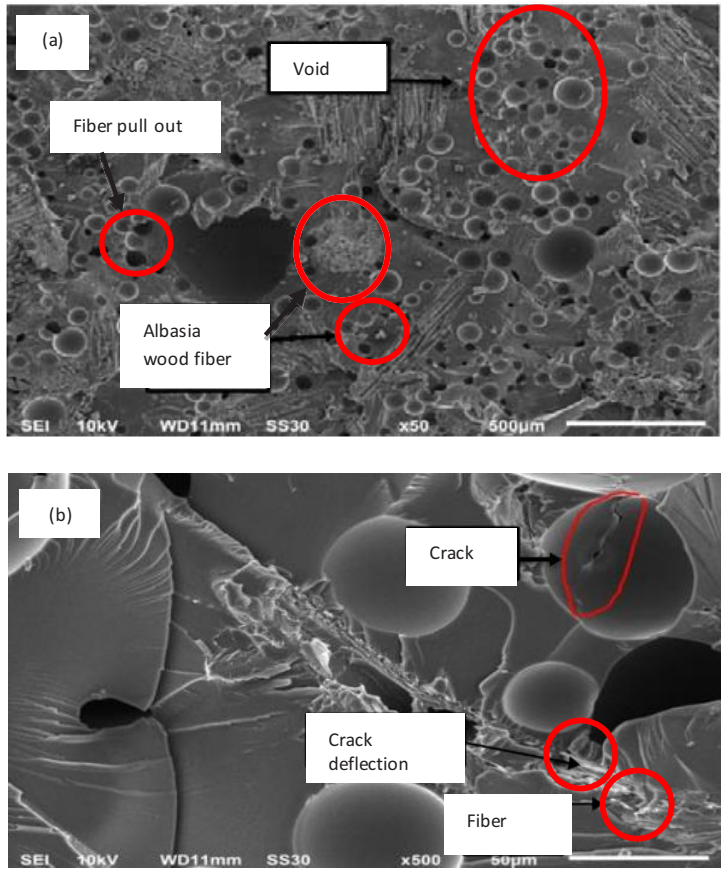

Figure 3 SEM micrographs of albasia wood-epoxy composites for the highest tensile strength value that shown: (a) void, (b) crack deflection

Meanwhile, the voids formation mechanisms of fiber reinforced composites were revealed by some researchers [10-16]. They reported that the voids were formed primarily due to several factors including mechanical air entrapment in the laminate during the layup process, moisture absorbed during the material storing, moisture dissolved in the resin and volatiles released by chemical reactions. Most of the voids were located in the center of the laminates due to the two open sides of the mold used. It was most difficult for the trapped air in the center to be discharged from the openings (Fig. 3 a).

From SEM micrograph of the fracture surface of specimen that has the highest tensile strength (specimen with mixing speed of $695 \mathrm{Rpm}$ and mixing time of 15 minutes) it could be seen that the crack resulted by cutting the specimen could initiate the crack propagation. However, because there is reinforcement (albasia wood), the crack could be deflected and stopped (Fig. 3 b). Fiber pull out could also be seen in the image. This fiber pull out could be due to the impurities on the fiber surfaces which lowered the surface wettability of the fiber against the resin matrix.

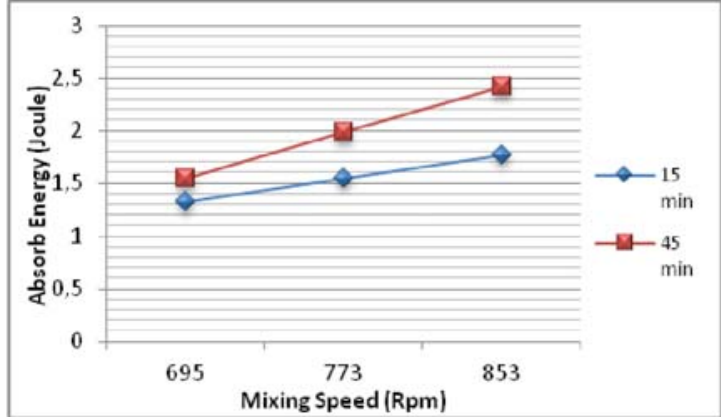

Figure 4 Impact strength test results of albasia wood-epoxy composites for different mixing speed and time

However, the result from impact test shows different results (Fig. 4). The energy absorbed, which means the impact strength, increases with the increasing of mixing time and mixing speed. It is because of the longer the mixing time and the higher the mixing rate, the better the wood distribution in the epoxy or in the other word, the fiber is distributed evenly in the matrix. This can enhance the toughness properties of material.

\subsection{Effects of Curing Temperature}

Curing is an irreversible reaction where chemical covalent cross-links are formed which thermally and mechanically stable. The composites that have $25 \%$ fiber volume fraction are used in this study where the curing temperature variations are $40^{\circ} \mathrm{C}, 50^{\circ} \mathrm{C}, 60^{\circ} \mathrm{C}, 70^{\circ} \mathrm{C}$, and $80^{\circ} \mathrm{C}$. The tensile and impact test have been done to investigate the effects of curing temperature to mechanical and morphological properties of epoxy-albasia wood composites.

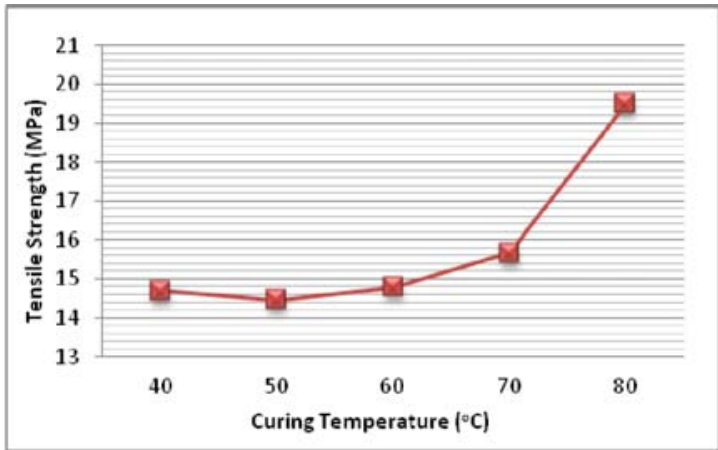

Figure 5 Tensile strength results of albasia woodepoxy composites for different curing temperatures 
The highest tensile strength was obtained when the composites was cured at $80^{\circ} \mathrm{C}$ (Fig. 5). From the experimental results, it also can be concluded that the increasing curing temperature improve the tensile strength. This could be caused by the evenly distributed of fiber, which has low density, in the epoxy resin matrix. It is commonly known that the curing process plays a major role in achieving the final mechanical properties and chemical resistance of the material, which complete cure is rarely achieved at room temperature. Not completed cure will reduce the performance of the material.

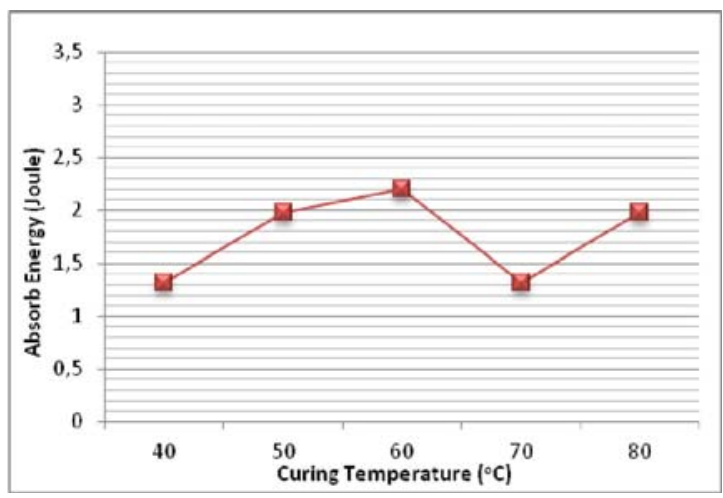

Figure 6 Impact strength test results of albasia wood-epoxy composites for different curing temperatures

One of the key issues in the use of fiber reinforced epoxy is the improvement of their fracture toughness at elevated temperatures. The impact test showed that the highest impact strength is obtained by curing temperature of $60^{\circ} \mathrm{C}$ (Fig. 6).

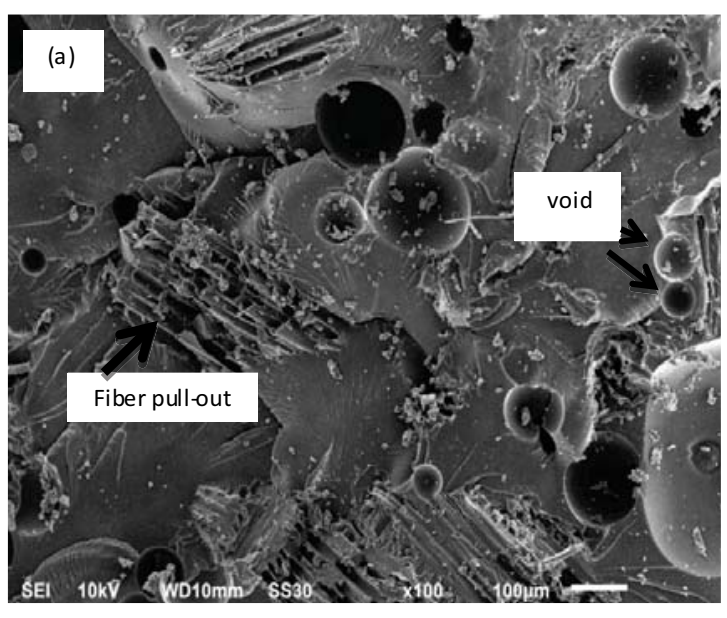

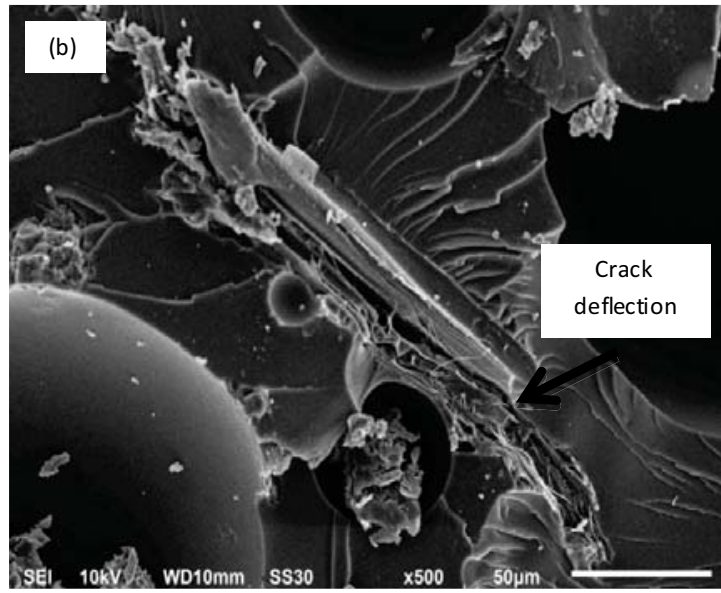

Figure 7 SEM micrographs of albasia wood-epoxy composites for the highest tensile strength value that shown: (a) void, (b) crack deflection

There is the decreasing impact strength resulted by the specimen with the curing temperature of $70^{\circ} \mathrm{C}$, but it is increasing again at curing temperature of $80^{\circ} \mathrm{C}$. This is possibly caused by the limitation of different fabrication technologies and processing parameters that produce some undesirable internal defects inside composites, such as voids, delamination, and resin-poor or resin-rich regions [17]. These defects had stress distribution effects on the materials/structures alone or together, which could weaken the mechanical properties of the composites [18]. It is also supported by the SEM micrographs of the tensile fracture surface (Fig. 7 a).

Eventhough there is void contained in the composite, the crack is deflected in $80^{\circ} \mathrm{C}$ curing time specimen that caused by the presence of fibers (Fig. 7 b). Therefore, the improvement in the toughness at $80^{\circ} \mathrm{C}$ curing time can be explained by crack deflection and the plastic deformation of the matrix material, which results in an increase in the crack propagation path and in the energy-dissipating events in the region immediately ahead of the crack tip. It is also supported by the investigation of Han and Cho [19]. They found that the toughness of an epoxy molding compound was found to be improved over a wide temperature range by the incorporation nanoparticles, and the fractographies of the fractured surfaces revealed that crack deflection and plastic deformation are the principal factors contributing to the observed toughening at high temperatures. 


\section{Conclusions}

The effects of mixing time, mixing speed and curing temperature on morphological and mechanical properties of epoxy-albasia wood fiber composites have been investigated.It is shown that mixing the fiber and matrix with the speed of 695 rpm for 15 minutes increases the tensile strength but slightly declines the impact strength which could be possibly caused by the longer the mixing time, the higher the amount of foreign particles entered into the mixture that could affect its properties. Eventhough the specimen with the speed of $695 \mathrm{rpm}$ for 15 minutes has the highest tensile strength, the presence of void could be seen by Scanning Electron Microscopy (SEM) micrographs results which cause poor distribution of stress between fiber and matrix that results in poor mechanical properties.Both the tensile and impact test show that the temperature of $80 \mathrm{oC}$ is the optimum curing temperature for epoxyalbasia wood fiber composites. Crack deflection showed by Scanning Electron Microscopy (SEM) micrographs of specimen that has the $800 \mathrm{C}$ curing time results in an increase in the crack propagation path and in the energy-dissipating events in the region immediately ahead of the crack tip which increase its fracture toughness.

\section{Acknowledgement}

The author would like to thank the Adisutjipto College of Technology for funding this project.The authors would like to thank Fajar Taufik and Sigit Diantoro for their support to this work.

\section{REFERENCES}

[1] May, C, Tanaka, T, 1973, Epoxy Resins Chemistry and Technology, Marcel Dekker Inc., New York.

[2] Lee, H, Neville, K, 1967, Handbook of Epoxy Resins, Mc Graw Hill, New York.

[3] Ellis, B, 1993, Chemistry and Technology of Epoxy Resins, Blackie\& Professional, New York.

[4] Sarawut, R, Watanachai, S, Saroj, J, Sunan, T, 2011, 'Highly Filled Polypropylene Rubber Wood Flour Composites', Engineering Journal, vol. 15, pp. $17-30$.
[5] Selke, S, Wichman, I, 2014, 'Wood/fiber polyolefin composites', Applied Science and Manufacturing, vol. 35, pp. 321-326.

[6] Tjondro, J, Budianto, H, Aryakusuma, W, 2011, 'The flexural strength and rigidity of albasia nail-laminated beam', Civil Engineering Forum Universitas Gadjah Mada, vol. 20, pp. 1211-1217.

[7] Michels ,J, Cruzc, S, Christend, R, Czaderskia, C, Motavallia, M, 2016, 'Mechanical performance of cold-curing epoxy adhesives after different mixing and curing procedures', Composites Part B: Engineering, vol. 98, pp. $434-443$.

[8] Jumahat, A, 2012, 'Tensile Properties of Nano Silica/Epoxy Nanocomposites', Procedia Engineering, vol. 41, pp. 1634-1640.

[9] Olivier, P, Cottu, J, Ferret, B, 1995, 'Effects of cure cycle pressure and voids on some mechanical properties of carbon/epoxy laminates', Composites, vol. 26, pp. 509-515.

[10] Liu, L, Zhang, BM, Wang, DF, Wu, ZJ, 2006, 'Experimental characterization of porosity and interlaminar shear strength in polymeric matrix composites', Chinese Journal of Aeronautics, vol. 26, pp. 115-118.

[11] Koushyar, H, Alavi-Soltani, S, Minaie, B, Violette, M, 2011, 'Effects of variation in autoclave pressure, temperature, and vacuumapplication time on porosity and mechanical properties of a carbon fiber/epoxy composite', Journal of Composite Materials, vol. 46, pp. 1985-2004.

[12] Liu, L, Zhang, BM, Wang, DF, Wu, ZJ, 2006, Effects of cure cycles on void content andmechanical properties of composite laminates, Composite Structures Journal, vol. 73 , pp. $303-309$

[13] Campbell, FC, Mallow, AR, Browning, CE,1995, Porosity in carbon fiber composites anoverview of causes,Journal of Advanced 
Material, vol. 26, pp. 18-33.

[14] Gu, Y, Li, M, Zhang, Z, Sun, ZJ,2010, Void formation model and measuring method ofvoid formation condition during hot pressing process, Polymer Composites, vol. 31, pp. 1562-1571.

[15] Grunenfelder, LK, Nutt, SR, 2010, Void formation in composite prepregs-effect ofdissolved moisture, Composites Science and Technology, vol. 70, pp. 2304-2309.

[16] White, SR, Kim, YK, 1996, Staged curing of composite materials, Composites Part A Applied Science, vol. 27, pp. 219-227.
[17] Zhang, LG, Zhang, ZG, 2001, 'Analysis of defects in advanced composites', Fiber Reinforced Plastic/Composites, vol. 1, pp. 42-45.

[18] Madsen, B, Thygesen, A, Lilholt, H, 2007, 'Plant fibre composites-porosity and volumetric interaction', Composites Science and Technology, vol. 67, pp. 1584-1600.

[19] Han, J, Cho, K, 2006, 'Nanoparticle-induced enhancement in fracture toughness of highly loaded epoxy composites over a wide temperature range', Journal of Materials Science, vol. 41, pp. 4239 - 4245. 